\title{
Advanced Neuroimaging with Computed Tomography Scanning
}

\begin{abstract}
Béatrice Claise ${ }^{1}$, Jean Gabrillargues ${ }^{1,4}$, Emmanuel Chabert1,4, Laurent Sakka3,4, Toufik Khalili,4, Vivien Mendes-Martins 3,4,

Viorel Achim³, Jérôme Costes ${ }^{3,4}$, Thierry Gillart2,4 and Jean-Jacques Lemaire ${ }^{3,4}$

${ }^{1}$ Neuroimaging Unit, Department of Radiology, University Hospital of Clermont-Ferrand, Hôpital Gabriel Montpied, B.P. 69, 63003 Clermont-Ferrand cedex 1 2Intensive Care Unit, Department of Anaesthesiolgy, University Hospital of ClermontFerrand, Hôpital Gabriel Montpied, B.P. 69, 63003 Clermont-Ferrand cedex 1 ${ }^{3}$ Department of Neurosurgery, University Hospital of Clermont-Ferrand, Hôpital Gabriel Montpied, B.P. 69, 63003 Clermont-Ferrand cedex 1 ${ }^{4}$ Univ Clermont 1, UFR Médecine, Image-guided clinical neuroscience and connectomics (ICCNC), Auvergne University, Clermont-Ferrand, F-63001
\end{abstract}

France

\section{Introduction}

For the first 20 years of clinical use, CT scan explored morphology of the body with axial slices. Within the head, CT-scan allowed to analyze broadly the brain like any organ of the body, whereas the skull like others bones was finely detailed.

The appearance of helical and multi-slice CT scans in the 1990's, with high speed processes, led to volumetric and dynamic data, such as angio CT and CT perfusion.

Since 2005, there has been a constant development in new techniques.

1. The improved travelling table systems allow thicker dynamic studies, especially useful for cerebral perfusion.

2. Dual energy allows reduction of metallic and bony artefacts, making possible to obtain material decomposition images (quantitative evaluation of density).

However, these improvements often lead to increased patient irradiation. Techniques aiming to limit this important drawback are currently being developed, allowing reducing irradiation dose.

We review the basic principles of advanced techniques, including irradiation dose reduction, and then describe their neuroradiological applications in daily practice.

\section{Material}

In our institution, we use a 40-mm CT scanner (General Electric Discovery CT 750 HD, with Gemstone Spectral Imaging and Volume Helical Shuttle Perfusion), with Adaptative Statistical Iterative Reconstruction (ASIR). 


\section{Dual-energy CT}

First experiments in Dual Energy CT (DECT), performed initially in the 1970s, demonstrated that DECT improved tissue characterization (Rutherford, Pullan, et Isherwood 1976). Until recently, this technology was impractical because of limiting factors such as insufficient spatial resolution, length of scan duration and important noise in the low-energy (lowkilovolts, low-kv) images. Two datasets must be acquired separately, at different times, increasing the risk of patient movements during the two phases that can reduce image quality (Thorsten R C Johnson et al. 2007).

Recent avdances in CT technology allow simultaneous acquisition of datasets at different energy levels (Coursey et al. 2010); such acquisitions have become possible either with two tubes mounted orthogonally, or with a generator able to switch between 80 and $140 \mathrm{kv}$ targets in a very short time, less than $0.5 \mathrm{msec}$.

\subsection{Principles}

In Computed Tomography, differenciation of materials or tissues depends on X-ray attenuation, which is a function of X-ray energy, determined by photoelectric effect and Compton scattering (fig.1)
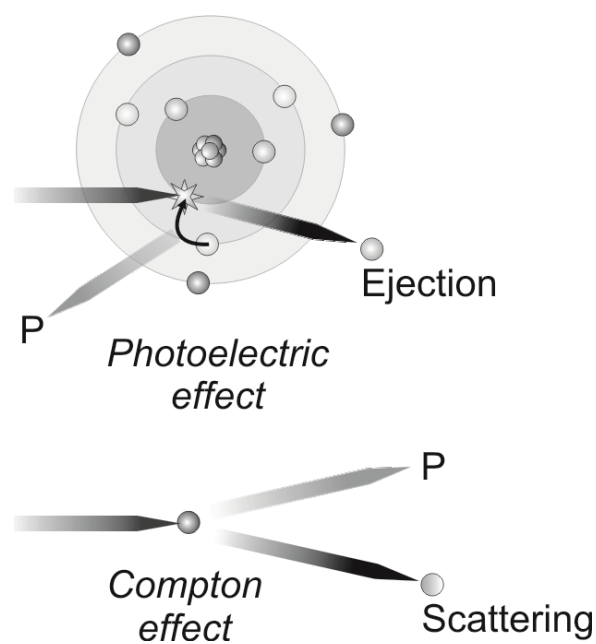

Fig. 1. The two main mechanisms of X-ray (blue line) attenuation are photoelectric effect and Compton effect. Photoelectric effect happens within electronic shells (layers) and consists in electron (colored sphere) ejection with concomittant emission of photon and reorganisation of electrons between shells. Compton effect happens with electrons which are scattered with concomittant emission of photon.

At the energy levels used in diagnostic imaging, Compton effect is almost independent of Xray photon energy, while photoelectric effect is strongly energy dependent (Sprawls Perry). The probality of photoelectric interaction increases as the energy is nearer to that of the $\mathrm{K}$ shell binding. The $\mathrm{K}$ edge is the energy level where there is a spike in attenuation, and which corresponds to energy levels just greater than that of the $\mathrm{K}$ shell binding. The $\mathrm{K}$ edge increases with the atomic number (Table 1) 
K Edges and Atomic Numbers of Physiologic Substances

and Contrast Agents

$\begin{array}{lcc}\text { Substance } & \text { K Edge }(\mathrm{keV}) & \text { Atomic Number (Z) } \\ \text { Hydrogen } & 0.01 & 1 \\ \text { Carbon } & 0.28 & 6 \\ \text { Nitrogen } & 0.40 & 7 \\ \text { Oxygen } & 0.53 & 8 \\ \text { Calcium } & 4.00 & 20 \\ \text { Iodine } & 33.20 & 53 \\ \text { Barium } & 37.45 & 56 \\ \text { Gadolinium } & 50.20 & 64\end{array}$

Table 1. Relationships between material atomic number and photon energy (Coursey et al. 2010)

DECT imaging relies on energy dependence of the photoelectric effect and on the variability of $\mathrm{K}$ edges. The optimal energies must be just greater than the $\mathrm{K}$ edge of substances explored (Coursey et al. 2010); using different energy levels, DECT allows distinguishing materials according to attenuation coefficients at selected energy levels.

Material decomposition (MD) does not identify stricto sensu materials. Material attenuation curve is indirectly studied using the linear combination of two other materials (fig.2). Thus given two arbitrary selected basic materials, MD determines how much of each material would be needed to produce the observed measurements at low (65 Kev) energy and high (140 $\mathrm{Kev})$ energy. These last two values correspond to common fixed DECT parameters of energy.

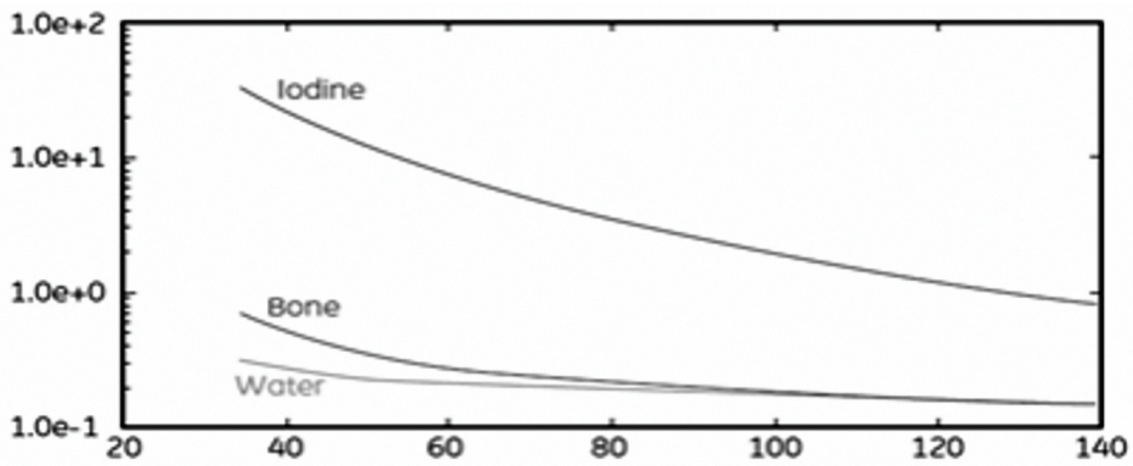

Fig. 2. The bone attenuation curve is a linear combination of iodine and water X-ray; $x$-axis, photon energy, Kev; $\mathrm{y}$-axis, mass attenuation coefficient, $\mathrm{m}^{2} / \mathrm{Kg}$ (from D.A.Langan, (Langan DA 2008)

For medical diagnosis, iodine and water are generally used, because they span the atomic number of the different materials that can be found in clinical practice.

\subsection{Pratical consequences}

Monochromatic spectral images obtained with DECT imaging are similar to that of a conventional Hounsfield unit image, but with fewer artefacts. This property is particularly useful to demonstrate implanted metallic devices such as coil, clip and electrode. In CT 
angiography, it can distinguish between contrast in a vessel and calcification; it also allows removing skull base bone artefacts (Watanabe et al. 2009).

With post-processing, monochromatic energy levels can be chosen within a range from 40 to $140 \mathrm{Kev}$. At high energy levels, material contrasting is limited, whereas at low energy levels, they are more important. This allows material differenciation and quantitative evaluation of density (Thorsten R C Johnson et al. 2007).

\section{Volume helical shuttle and CT brain perfusion}

\subsection{Principle of Volume Helical Shuttle (VHS)}

With the latest generation of multidetector CT scanners, it is possible to cover large volumes of anatomy in a very short time. As a consequence, a thick portion of the brain is explored.

However, when width of coverage increases, it might increase phenomenas such as cone beam artefact (wide cone angle for wide-area detector), heel effect (non-uniform illumination of X-ray of the tube anode for wide-area detector) and scatter of X-ray photons. These inconveniences are reduced by VHS, which is a new adaptative technology enabling the CT table to travel back and forth using continuous periodic table movement during the acquisition (fig.3).
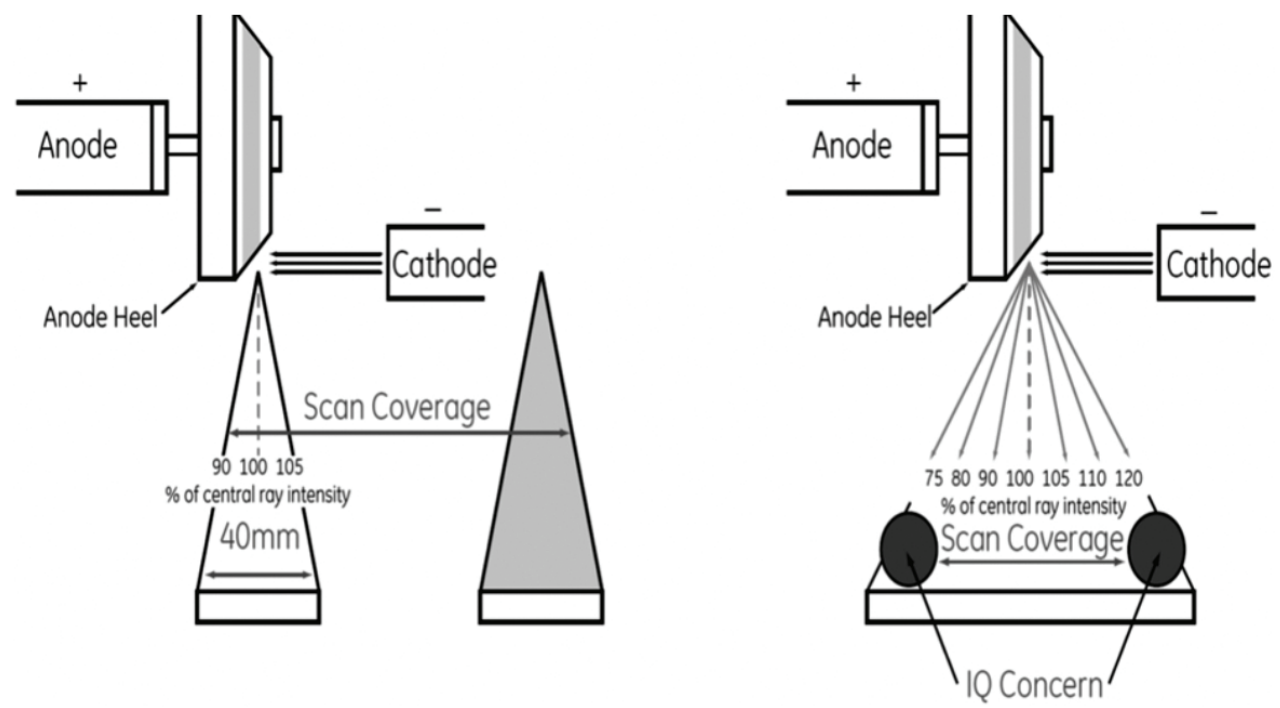

Fig. 3. Volume helical Shuttle (VHS, left) compared to wide-coverage detector axial acquisitions (right): there is no image quality (IQ) concern with VHS, whereas with widecoverage detetector IQ concerns, as well as heel effect, cone beam artefact and increase photon scaterring, are known (from A. Hagiwara, 2008)

VHS affords minimal overscanning, consequently reducing unnecessary radiation exposure, (fig.4). VHS also improves temporal sampling; for maximum scan coverage of $312.5 \mathrm{~mm}$, the system realizes 20 passes (10 round trips) within $60 \mathrm{sec}$, with a temporal sampling of $2.9 \mathrm{sec}$ at the center of the volume. 


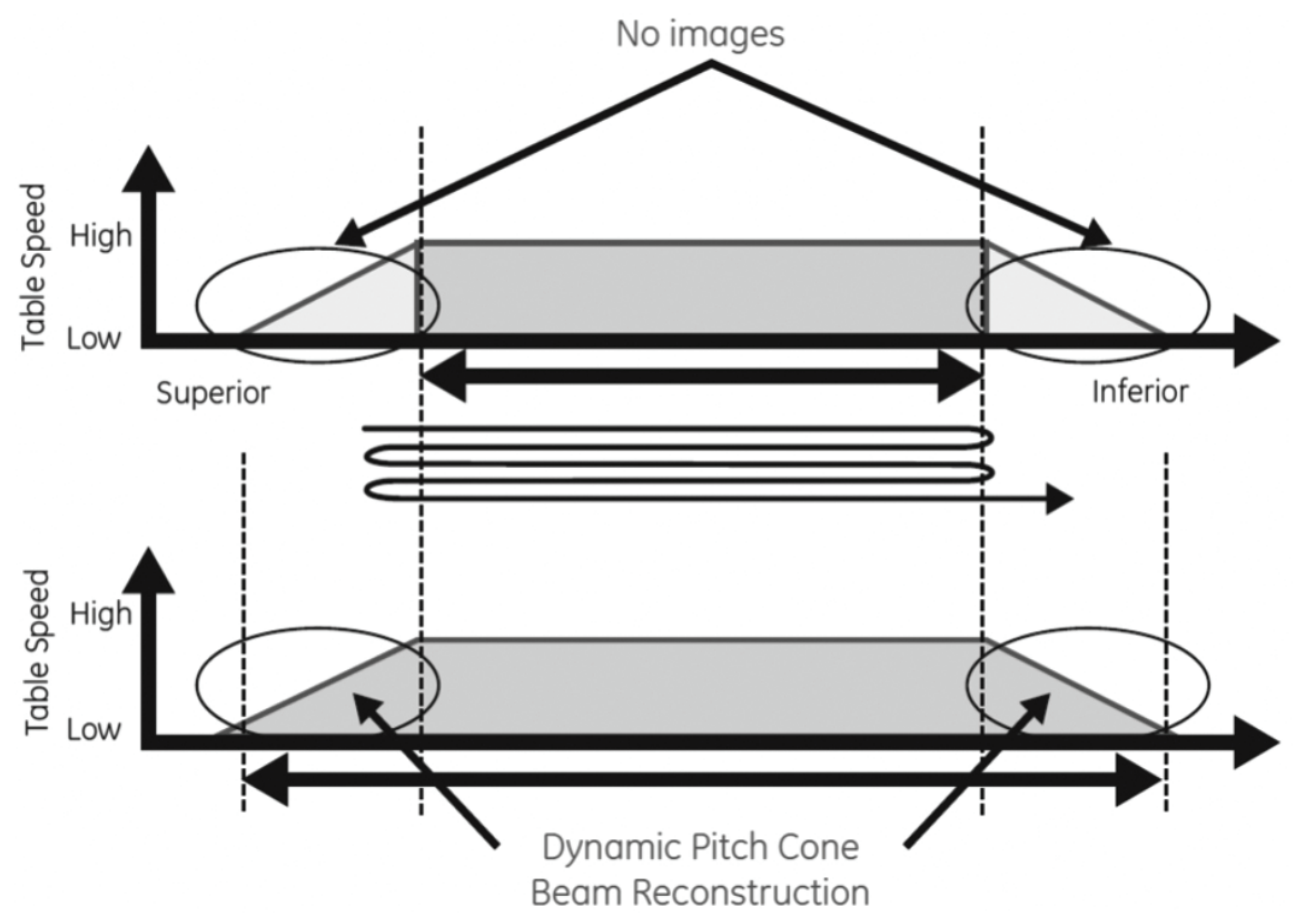

Fig. 4. There is no overscanning with Volume Helical Shuttle (top) conversely to conventional helical scanning (bottom) (from A. Hagiwara, 2008)

\subsection{Principle of CT brain perfusion}

VHS main application in neuroimagery is CT brain perfusion.

Until today, maximum coverage allowed in a sufficient temporal resolution was of $20-\mathrm{mm}$ thickness for four detector-rows CT, and $80 \mathrm{~mm}$ for sixteen detector rows. With VHS technology, the coverage for brain CT perfusion is $120 \mathrm{~mm}$, obtained in less than $48 \mathrm{sec}$, with a temporal resolution of $0.2 \mathrm{sec}$.

For many years, CT and MRI have been used for structural information. After the development of perfusion MRI, CT perfusion has been perfected and these two modalities now allow assessment of haemodynamic characteristics in brain tissue.

CT perfusion consists in analysis of the time evolution of contrast agent during the first passage of an intravenous bolus of iodine (Grand et al. 2007) (Hoeffner et al. 2004). Scans are obtained in dynamic mode during the injection. Functional data of brain perfusion are automatically calculated according to the central volume principle, which relates cerebral blood volume (CBV), cerebral blood flow (CBF) and mean transit time (MTT) in the following equation: $\mathrm{CBF}=\mathrm{CBV} / \mathrm{MTT}$. MTT is given by deconvolution of tissue enhancement curves with reference to an arterial curve, generally obtained in the anterior cerebral artery (fig. 5). For each parenchymal pixel, CBV is calculated as the area under the curve divided by the area under the curve in the arterial ROI. Then, CBF is calculated according to central volume equation. 

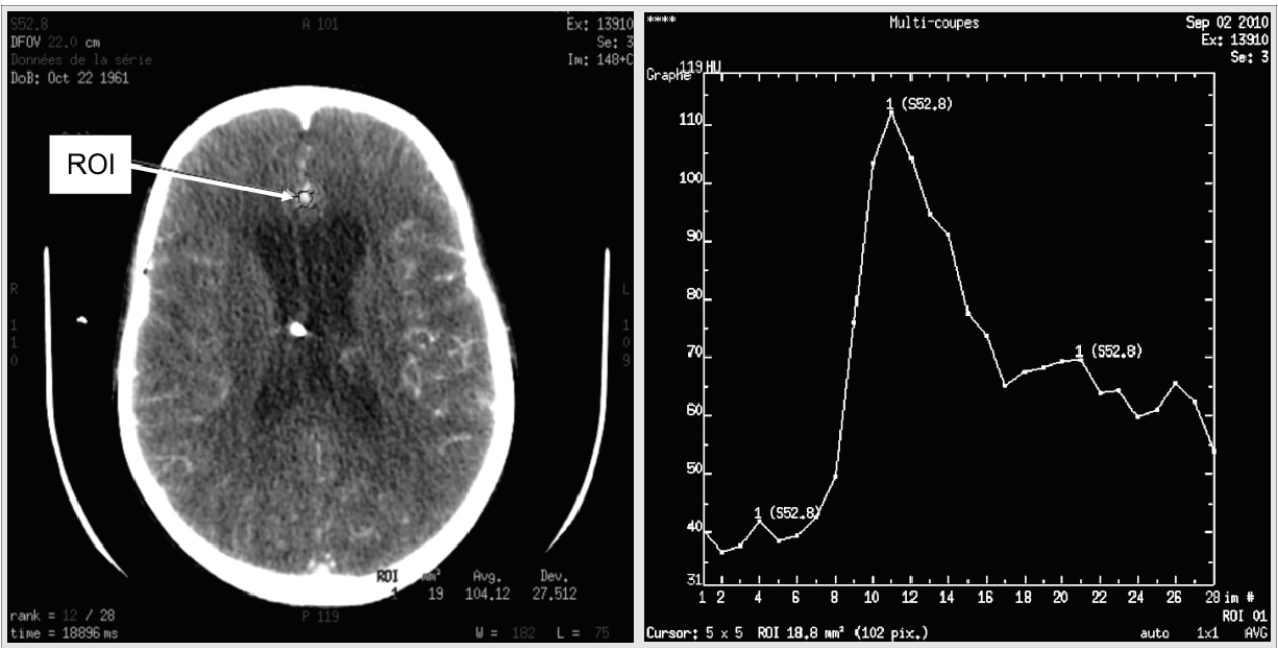

Fig. 5. Time-concentration curve. The anterior cerebral artery is generally choosen as the input artery (ROI, left), and time-concentration curve is generated from data within the ROI pixels (right; in this example the ROI comprises 102 pixels; $x$-axis, image number; $y$-axis, Hounsfield unit).
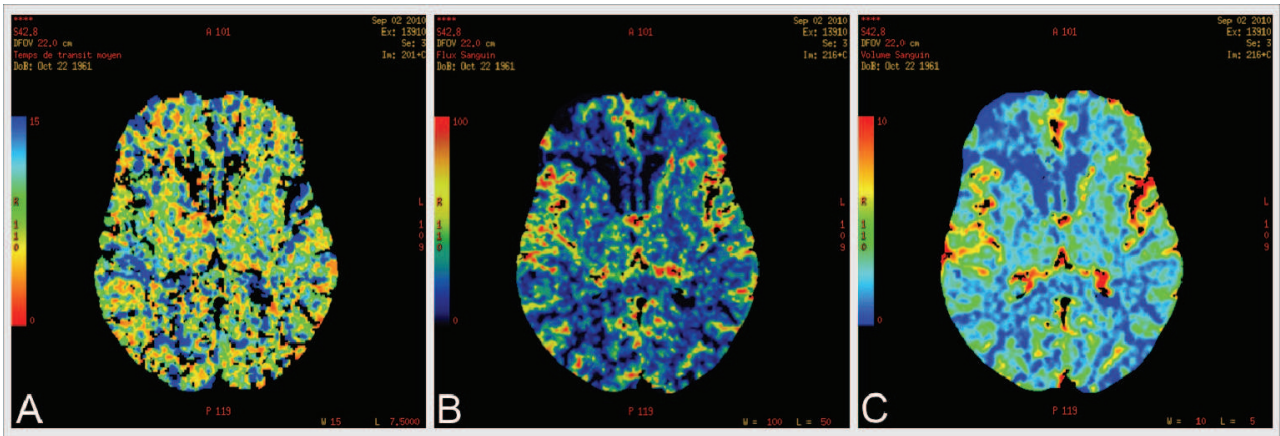

Fig. 6. (A) Mean Transit Time color map, msec, from 0, red, to 15, blue; (B) Cerebral Blood Flow color map, $\mathrm{ml} / \mathrm{msec}$, from 0 , blue, to 100, red; (C) Cerebral Blood Volume color map, $\mathrm{ml}$, from 0 , blue, to 10 , red. (Normal data)

A parameter related to vascular dynamics process has also been introduced, namely Permeability Surface Area Product (PS), which evaluates the flow of contrast agent crossing the capillary wall between intravascular and extravascular compartments.

This trans compartment flow is often called blood vessel leakness or blood clearance of contrast agent and is extrapolated from Patlak graphical analysis used for glomerule filtration rate exploration (Dawson 2006). The formula is as follows: $P S=P \times S$; $P$ (permeability) $=\mathrm{D} / \mathrm{t}$, with $\mathrm{D}=$ diffusion coefficient of contrast agent, and $\mathrm{t}=$ thickness of endothelium; $S=$ surface of capillary tree.

PS is expressed in $\mathrm{ml} / 100 \mathrm{~g}$ of tissue / min. A voxel-wise approach leads to PS map (Fig. 7) 


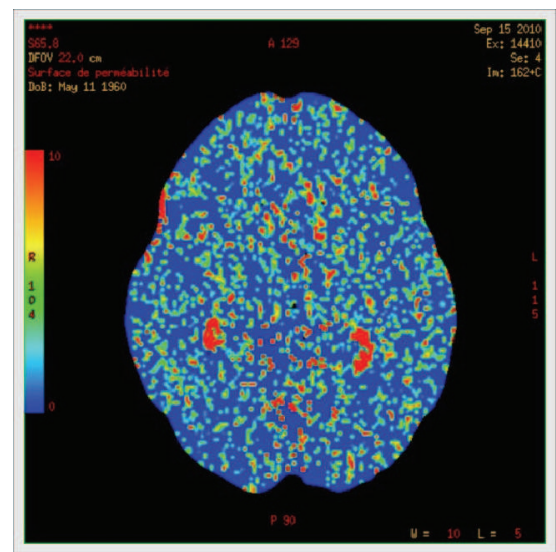

Fig. 7. Permeability Surface Area Product (PS) map, from 0, blue, to 10, red, in ml / $100 \mathrm{~g}$ of tissue / min (normal data)

CT perfusion presents some advantages compared with magnetic resonance imaging (MRI) perfusion:

- It allows qualitative and quantitative analysis, by giving absolute values of brain perfusion.

- Patient access is generally easier and CT perfusion is easy to perform; thus CT perfusion can be the initial exploration.

- Spatial resolution is good; voxel size is about 1-2mm.

- Results are obtained in less than $15 \mathrm{mn}$.

The main limitation of CT perfusion was the thickness of coverage, which is of $20 \mathrm{~mm}$ for a 4-detector row and $80 \mathrm{~mm}$ for a 16-detector row) (Grand et al. 2007)). VHS now allows coverage of $120 \mathrm{~mm}$ of the brain, with a temporal resolution of 1 image every $3 \mathrm{sec}$.

The main drawbacks are the risk of radiation overexposures and adverse effects due to iodinated contrast agent.

\section{Reducing radiation dose in CT neuroimagery: use of adaptative statistical reconstruction algorithm (ASIR)}

Since the inception of CT, the number of CT scans per year has dramatically increased (Brenner et Hall 2007). This results from its large availability, speed and diagnostic benefits. The drawback was increased radiation doses, requiring new techniques reducing these doses while improving diagnosis performances.

Reconstruction algorithms currently used such as filtered back projection (FBP) are unable to generate diagnostic quality images if $\mathrm{X}$-ray tube currents decrease because signaldifference-to-noise ratio decreases with low-dose CT.

One alternative is iterative reconstruction technique (McCollough et al. 2009)(Silva et al. 2010) perfected with an adaptative statistical iterative reconstruction technique (ASIR), which limits computing time.

ASIR uses information obtained from the FBP algorithm and then uses matrix algebra to transform the value of each pixel to a new estimate of the pixel value. This new pixel value is then comparated with the ideal value predicted with the noise model. Iterations are 
successively performed until final estimated and ideal pixel values converge (Silva et al. 2010)(Hara et al. 2009). It is possible to blend ASIR and FBP images in a range of $10 \%$ to 100\%(Leipsic et al. 2010)(Flicek et al. 2010) .

Recent studies have demonstrated that ASIR reduces noise and improve signal-differenceto-noise ratio. By applying an appropriate percentage of ASIR, radiation doses are reduced between 23\% to 65\% (Leipsic et al. 2010)(Flicek et al. 2010)(Sagara et al. 2010)(Prakash et al. 2010).

\section{Medical Neuroimaging}

\subsection{Applications of CT perfusion \\ 6.1.1 Acute stroke}

Recent advances in thrombolytic therapy, allowing reperfusion of brain tissue, have fostered the identification of biological parameters witnessing of reversible cell damage within the hypoperfused territory. Restoration of normal cell activity depends on severity of cell damage and on blood supply, particularly oxygen content and cerebro-vascular autoregulation. The tissue tolerance of CBF reduction ranges from $20 \mathrm{ml} / 100 \mathrm{~g} / \mathrm{min}$ to $6-10$ $\mathrm{ml} / 100 \mathrm{~g} / \mathrm{min}$; below $6-10 \mathrm{ml} / 100 \mathrm{~g} / \mathrm{min}$, cell damage and synaptic conduction may be irreversible, leading to infarction; below $20 \mathrm{ml} / 100 \mathrm{~g} / \mathrm{min}$, often called the "penumbral flow threshold", damage may be reversible (Zaro-Weber et al. 2009)

One of the challenges is to identify the area where the cerebro-vascular autoregulation is maintained, because of the likelihood to reverse non-lethal cell damage. CT perfusion can determine this penumbra area, defined by normal or elevated CBV, while CBF is decreased and MTT is increased because of hypoperfusion (Max Wintermark et al. 2002).

The infarct core, i.e. area of irreversibility of damaged tissue, is characterized by the loss of cerebro-vascular autoregulation, and defined by decreased CBV, decreased CBF and increased MTT; (Grand et al. 2007)(Hoeffner et al. 2004)(Schramm et al. 2004)(Schaefer et al. 2006)(Mejdoubi, Calviere, et Dumas 2010) (fig.8).

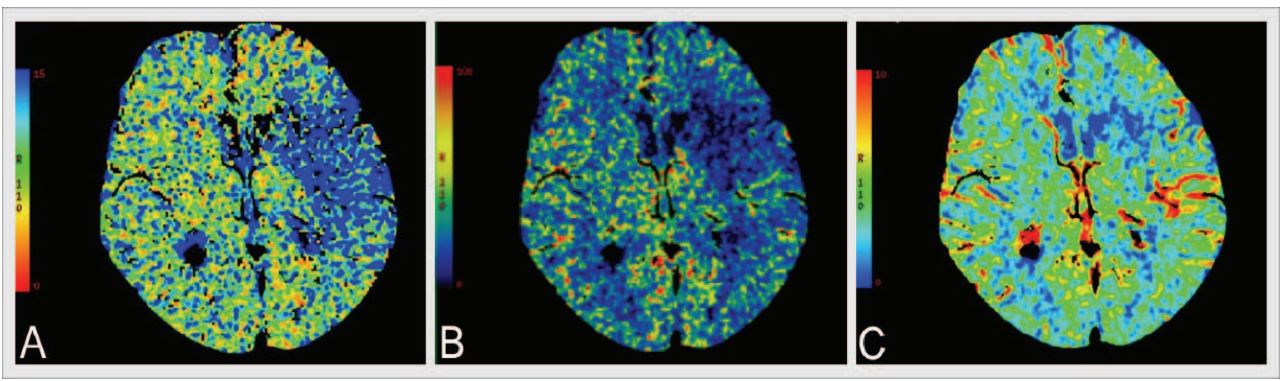

Fig. 8. Recent stroke in the left middle cerebral artery territory. Infarct tissue has elevated MTT (A), decreased CBF (B) and decreased CBV (C). Note the mismatch between the infarct area and the tissue at risk of infarction, which corresponds to the area where CBV is maintained and MTT is increased.

Patients with acute stroke can benefit from reperfusion therapy if undertaken before six hours, if the size of infarct area is less from one third of the middle cerebral artery territory, and if there is a minimal mismatch ratio of $20 \%$, between the infarct core and the penumbra, hence more than $20 \%$ of the hypoperfused region could recover (Furtado et al. 2010). In 
addition, mismatch ratio increases with the z-axis coverage, or thickness, of CT Perfusion (Furtado et al. 2010). Consequently, increasing coverage of CT Perfusion, improves accuracy of functional data; it also prevents missing a lesion by incorrect selection of the tissue block analysis.

The most sensitive criteria of early detection of ischemia seems the relative increase of MTT, compared with controlateral safe hemisphere, higher than $145 \%$, and the most accurate parameter to determine infarcted area seems a CBV value under $2 \mathrm{ml} / 100 \mathrm{mg}$; the mismatch between areas with a CBV lower than $2 \mathrm{ml} / 100 \mathrm{mg}$ and areas with increased MTT allows the most accurate delineation of tissue at risk of infarction (Max Wintermark et al. 2006).

Another recent study shows that the risk of hemorrhagic transformation in acute stroke patients is correlated with increased PS (Aviv et al. 2009)

CT angiography (CTA) is usually performed during the same session to determine stroke etiology, intra or extracranial vessel occlusion or dissection, and occlusion location. Conventional CTA images are well known to have poor quality in skull base region (Ma et al. 2010). In DECT acquisitions, value of iodine increases much more than bone or calcium with decreasing of X-ray tube voltage. By varying the values of $\mathrm{Kev}$ on Material Decomposition images, skull base bone artefacts are exclude, while keeping good contrast in the lumen of arteries, and vascular calcifications are removed, allowing to insulate the lumen vessel (Thorsten R C Johnson et al. 2007) (Coursey et al. 2010)(Watanabe et al. 2009). Finally, CT is a reliable and accurate technique to explore patients with acute stroke, combining CT without injection to exclude intracranial haemorrhage, CT Perfusion to evaluate penumbra, and CTA to determine the etiology of ischemia (Grand et al. 2007)(Hoeffner et al. 2004)(Furtado et al. 2010).

However, CT may be insufficient for lacunar or brainstem infarction and also to determine directly cell damage.

\subsubsection{Vasospasm}

Vasospam is a complication of aneurysmal subarachnoïd hemorrhage that can worsen the prognosis. Severe vasospasm can lead to delayed cerebral ischemia (DCI) and symptomatic vasospasm, this latter can lead to delayed ischemic neurologic deficit (DIND); one can bear in mind that the relationship between vasospasm and DIND is not straightforward (AlTamimi et al. 2010)

The diagnosis of vasospasm and DCI stays difficult to establish and often delayed. Currently, the gold standard of arterial vasospam diagnosis is conventional angiography, and the survey of patients relies mainly on clinical examination and transcranial Doppler. Recent studies show that CT Perfusion is useful and reliable to assess vasospasm and DCI, vasospasm induces increased MTT and further decreased CBV (Grand et al. 2007)(Dankbaar et al. 2009)(van der Schaaf et al. 2006)(M Wintermark, N U Ko, et al. 2006).(Max Wintermark et al. 2008). MTT seems the most sensitive parameter to detect regions at risk to vasospam (M Wintermark, N U Ko, et al. 2006) (Pham et al. 2007) (Max Wintermark et al. 2008) (fig.9).

In addition, CT Perfusion is repeatable at regular intervals with reproductible parameters, making it useful in this critical period, while taking into account risk of radiation overexposures and adverse effects due to iodinated contrast agent.

VHS can help to detect directly the vasospasm on the vascular tree during CTA, allowing wider exploration of vascular territories. DEACT reduces artefacts generated by metallic clips or coils enabling better analysis of vessels (fig.10); it also removes bone artefacts. 


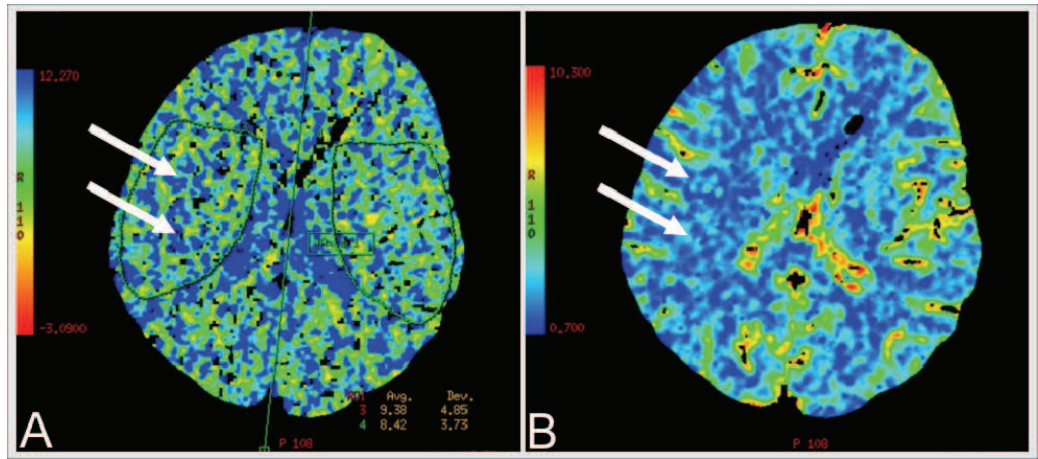

Fig. 9. CT Perfusion performed seven days after intravascular embolisation of anterior communicant artery aneurysm revealed by subarachnoïd hemorrhage: increased MTT (A) associated with decreased CBV (B) in right middle cerebral artery territory (white arrows) is the result of vasospam.

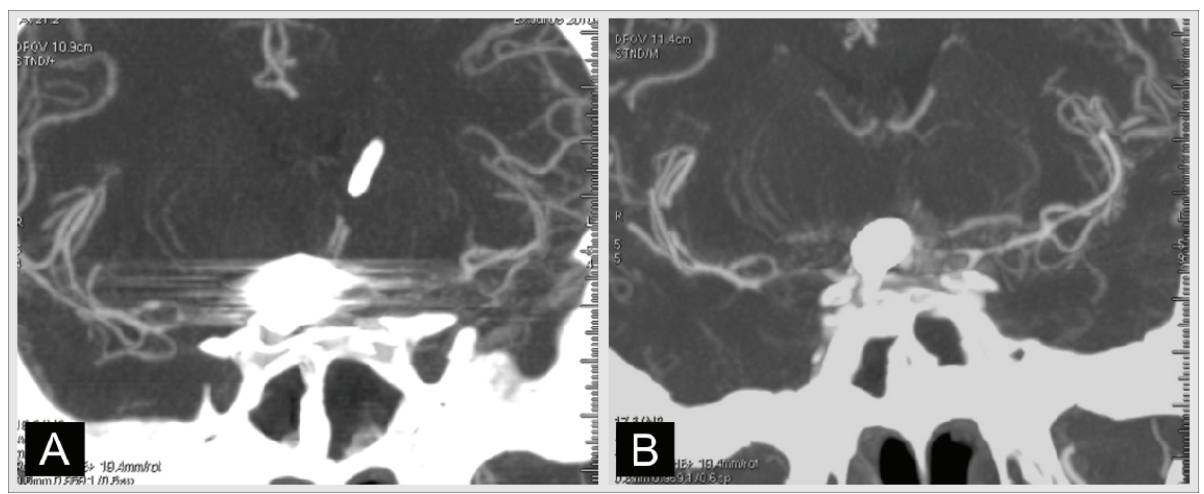

Fig. 10. Using DEACT (B) removes most of artefacts visible on current CT acquisition (A); same patient than in fig. 8 .

Compromise must be found when increasing Kev to reduce artefact, because this can lead a false reducing of vascular luminal diameter, mimicking a vasospasm.

\subsubsection{Tumors}

It is challenging to determine the bio-architecture of brain tumor. Modern non invasive imaging techniques allow estimating many biological parameters, which must be interpreted cautionly and compared with histological findings, which are still the gold standard for tumor classification (Scheithauer, Fuller, et VandenBerg 2008). Among bioarchitectural parameters, such as cell proliferation and energetic metabolism, vascularization is of upmost importance since it was demonstrated that it could be an important prognostic factor, nowdays easily accessible with non invasive imaging (Scheithauer, Fuller, et VandenBerg 2008).

However the word vascularisation covers different conditions, such as hypervascularization, neo vascularization whatever the cause (e.g. tumor growth, tumoral 
vessels, radionecrosis) and blood brain barrier (BBB) dysfunction up to permanent rupture. Imaging perfusion allows quantifying CBF, CBV, MTT and PS product that could be usefull to show differences between diverse brain tumors and to determine non-invasive prognostic factors.

Thus, for the last few years, studies of MRI perfusion imaging have shown correlation between increasing of regional CBV (rCBF), Permeability Surface-area product (PS) and grading of tumors (Grand et al. 2007)(Hoeffner et al. 2004)(R Jain et al. 2008)(Law et al. 2003)(Ding et al. 2006). CNS lymphomas have intense contrast enhancement with increased PS product whereas CBV remains low (Schramm et al. 2010). In gliomas, perfusion imaging could also be useful to guide the biopsy where there is the greatest increasing of rCBV and PS (Grand et al. 2007) .

Lastly, it can assess the response to treatment (besides the tumoral volume), and differentiate tumor recurrence from radionecrosis(Grand et al. 2007) (see e.g fig.11)

One of the main advantage of CT Perfusion compared with MRI is the quantitative assessment of PS. Poor anatomical definition remains a drawback of this technique, and additional studies are required to validate results; however it seems to be a good alternative or complement to MRI perfusion imaging, especially to obtain quantitative data.
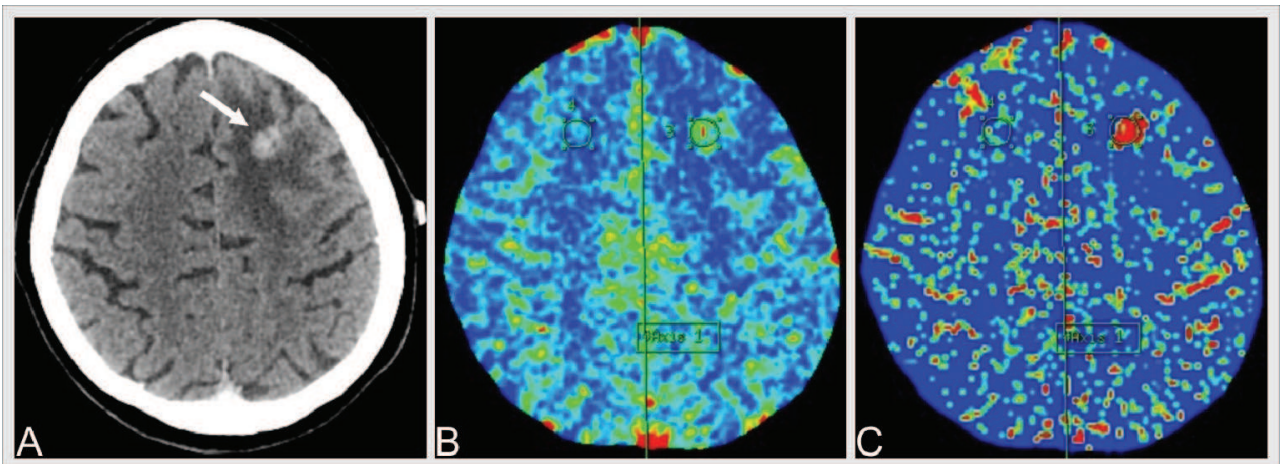

Fig. 11. CT Scan (iodinated contrast injection) performed 2 years after fractionated radiotherapy for a frontal metastasis (A) shows a contrast-enhancing lesion (white arrow); CT perfusion has revealed increased CBV (B) and increased PS (C) favoring tumor recurrence confirmed by histopathological analysis.

\subsubsection{Other applications of vascular imaging}

CT Perfusion is a non-invasive way to characterize cerebral vascular autoregulation, and could hence be used to adjust and monitor brain oedema therapy following head injury (M Wintermark, Chiolero, et al. 2006). In this indication, VHS is always interesting to study a greater width of cerebral parenchyma.

Time aspect given by perfusion imaging can be used to obtain dynamic images of cerebral blood flow (fig.12)

This technique is not a current practice because of the volume of data lending long reconstruction time. However, it seems interesting in specific indications, such as arterioveinous malformation for diagnosis and volume survey of vascular nidus after treatment. 


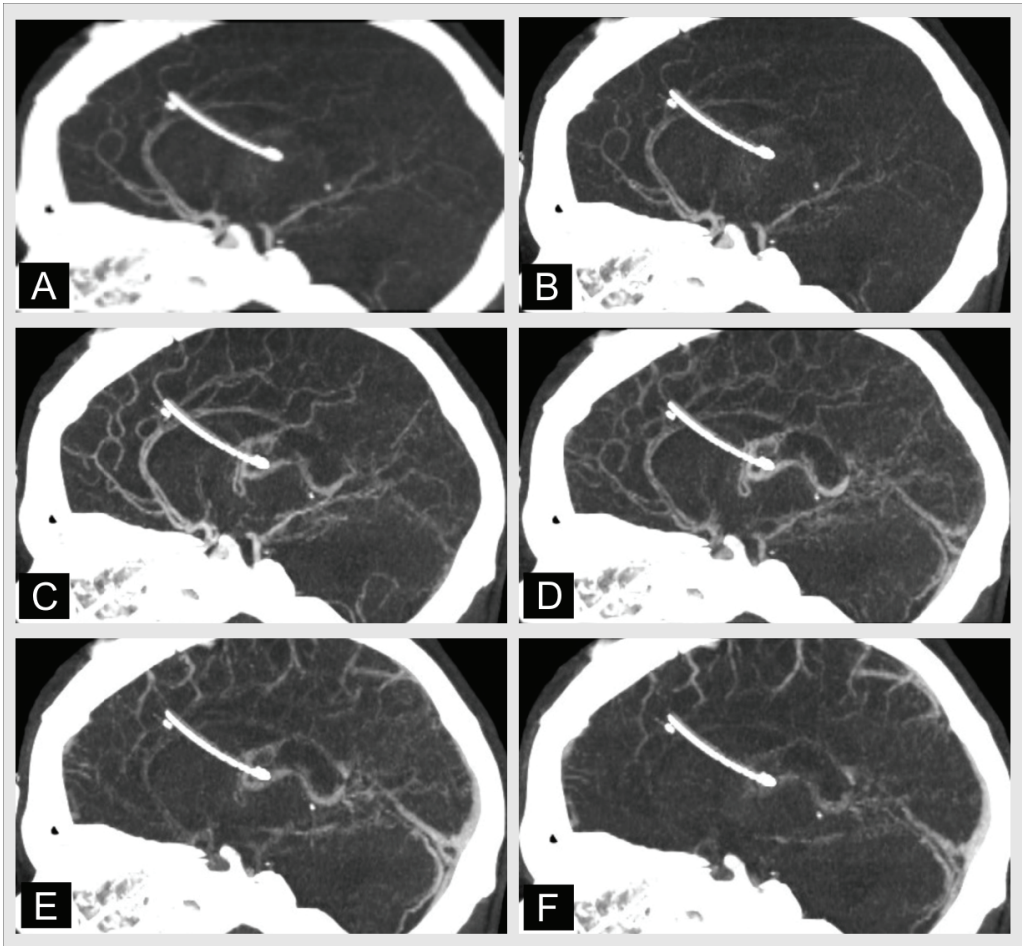

Fig. 12. Dynamic CT acquisitions show the circulation of iodinated contrast agent in the vessels: from arterial time (A) to venous time $(F)$. An intraventricular catheter (white) is visible.

\subsection{Analysis of contacts of deep brain stimulation electrodes: a predictable using of spectral CT}

Groups performing brain stimulation advocated post-operative imaging, MRI or CT to analyse the anatomic position of each electrod contact (F Caire et al. 2006)(Duffner et al. 2002)(Ferroli et al. 2004)(Lemaire et al. 2007, a) (Pinto et al. 2007)(Vayssiere et al. 2004).

We studied the artefact generated on CT scans by the contacts of the DBS 3389 electrode (Medtronic, Mineapolis, USA) (Hemm et al. 2009). In vitro-study showed that the distal and proximal limits of a lateral black artefact represented the four contacs of the electrode. In vivo-study confirmed that the artefacts are reliable to define the position of the fours contacts. Phantom and patient CT acquisitions showed the presence of three other sorts of artefacts: a white artefact corresponding to the electrode, a lateral black artefact around a part of the electrode due to the large difference in density between the contact and the surrounding tissue, and zones of protuberance of the white artefact, corresponding to the transition from metal to insulation (unlike for MRI, where the biggest artefact correspond to the contact of the electrode). From these observations, three measurements were carried out: height of the lateral black artefact $(\mathrm{H})$, distance between the begining of the white and the lateral black artefact (D), maximal artefact width (W), representing respectively the lengths of the four contacts, the electrode tip and width of the contact zone (fig. 13) 


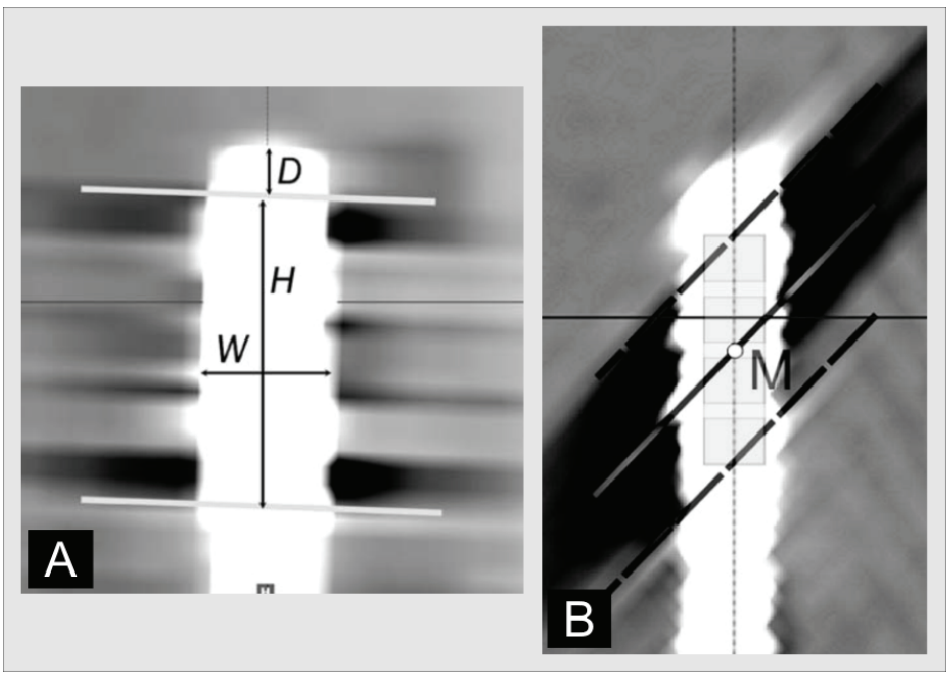

Fig. 13. A. Illustration of the different artefact parameters measured on phantom and patient CT acquisitions; $\mathrm{W}$, maximal width of the white electrode artefact, $\mathrm{H}$ height of lateral black artefact along the electrode axis, D, distance between the beginning of the white electrode artefact and the beginning of the lateral black artefact (Hemm et al. 2009). B. After identification of the distal and proximal black artefact boundaries (dotted lines), the location of the four contacts is determined relatively to the point $(\mathrm{M})$ placed in the middle of the distance between the two boundaries (Hemm et al. 2009).

The width of the artefact was nearly twice the theorical electrode diameter because of X-ray diffusion. There was no difference between pseudo-sagittal and pseudo-coronal reconstructions along the electrode axis; however there is a slight influence of the second electrode in the pseudo-coronal direction. Consequently, contact positions analysis relied on (fig.13.B): identification of the end of the distal contact corresponding to the distal boundary of the lateral black artefact, the tip length of approximately $1.2 \mathrm{~mm}$ can be used to validate the beginning of this black artefact; identification of the beginning of the proximal contact corresponding to the proximal boundary of the lateral black artefact; calculation of the four contact locations, according to the known electrode geometry.

This study demonstrates that post-operative CT scan in implanted patients is a useful alternative to MRI. In addition, CT offers some advantages over MRI: shorter acquisition time $(<1 \mathrm{~min}$ versus $5 \mathrm{~min}$ ), greater accessibility and lower cost. MRI-CT coregistration allows optimizing post operative data using with the best contact analysis on CT and the best anatomical analysis on MR (Lemaire et al. 2007,b). There are also safety issues for both techniques: Specific Absorption Rate (SAR) can be a problem for MRI because the presence of a metallic implant carries a potential risk of electrode displacement or of heating under a high magnetic field (Gleason et al. 1992)(Schueler et al. 1999)(Uitti et al. 2002), and CT uses ionising radiations.

Further studies are mandatory to reduce electrode artefacts. First measurements made with DEAC technology seems promising, reducing dramatically artifacts; MRI-CT coregistration and refined electrode analysis suggest that we will have nearly real visualization (fig 14), allowing better understanding of deep brain stimulation mecahnisms. 

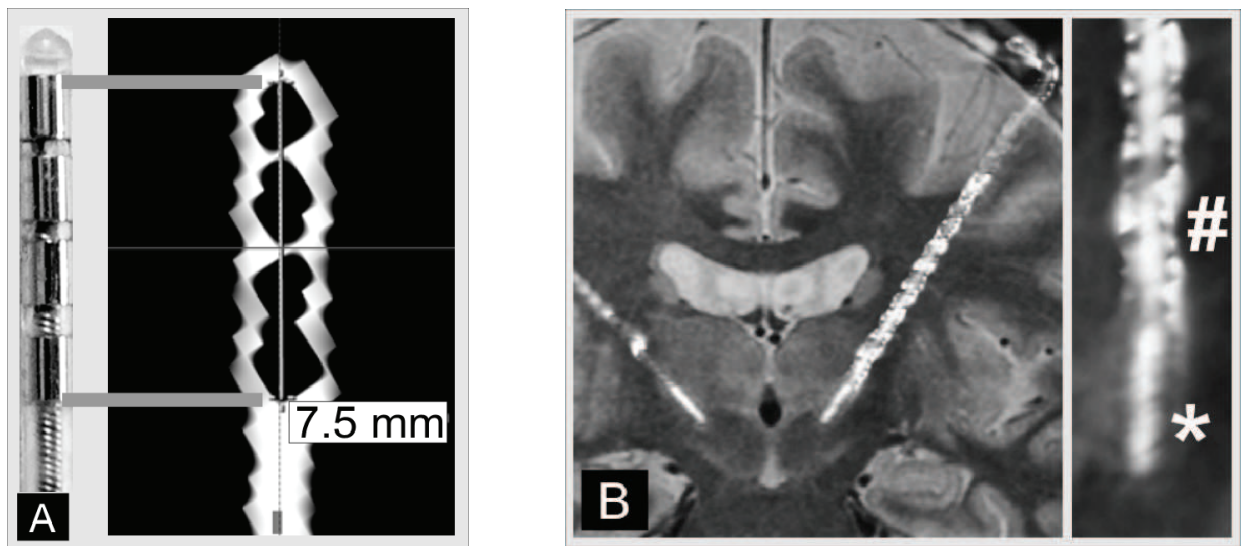

Fig. 13. DEAC monochromatic images are close to reality: (A) reconstructed image along the electrode (DBS 3389), showing artefacts of contacts; B, coregistration of electrode artifact extracted from DEAC images with pre operative MRI, on the right, zoom in of the electrode artifact showing details of the tip $\left(^{*}\right)$ and twisted electride wires (\#).

\subsection{Material decomposition}

Multi-Energy CT enables measurement of material density using spectral images, namely Material Decomposition (MD). MD allows separation and characterization of different materials with similar CT density values (Hui et al. 2010). In clinical neuroimaging, this technique can be used for several purposes such as differenciate iodine in the vessel lumen from wall calcifications (Coursey et al. 2010) (Fig.14) and differentiate intracerebral hemorrhage from iodinated contrast (Rajiv Gupta et al. 2010) (fig.15)

Density measurement of products using multi-energy opens prospects in biomedical research. For instance, it is possible to determine physical properties of gels, such as density (mg/cm3) and homogeneity (fig. 16)(Saliege et al. 2010)
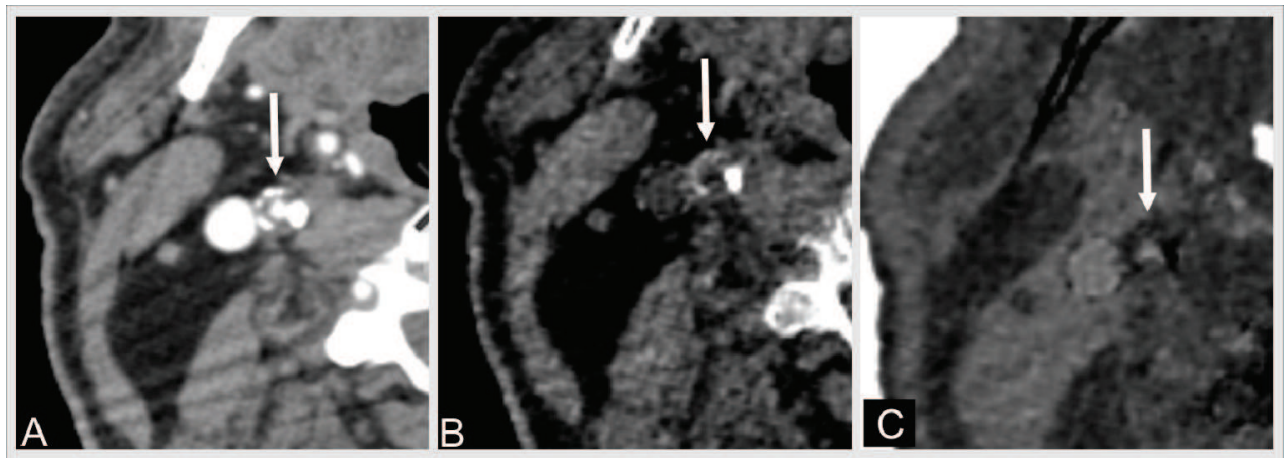

Fig. 14. Carotid (white arrow) CTA: (A) $70 \mathrm{KeV}$ monochromatic image; (B) calcium density windowing; $(C)$ iodine density windowing. Data transformation into effective material densities (MD) improves tissue characterization. 


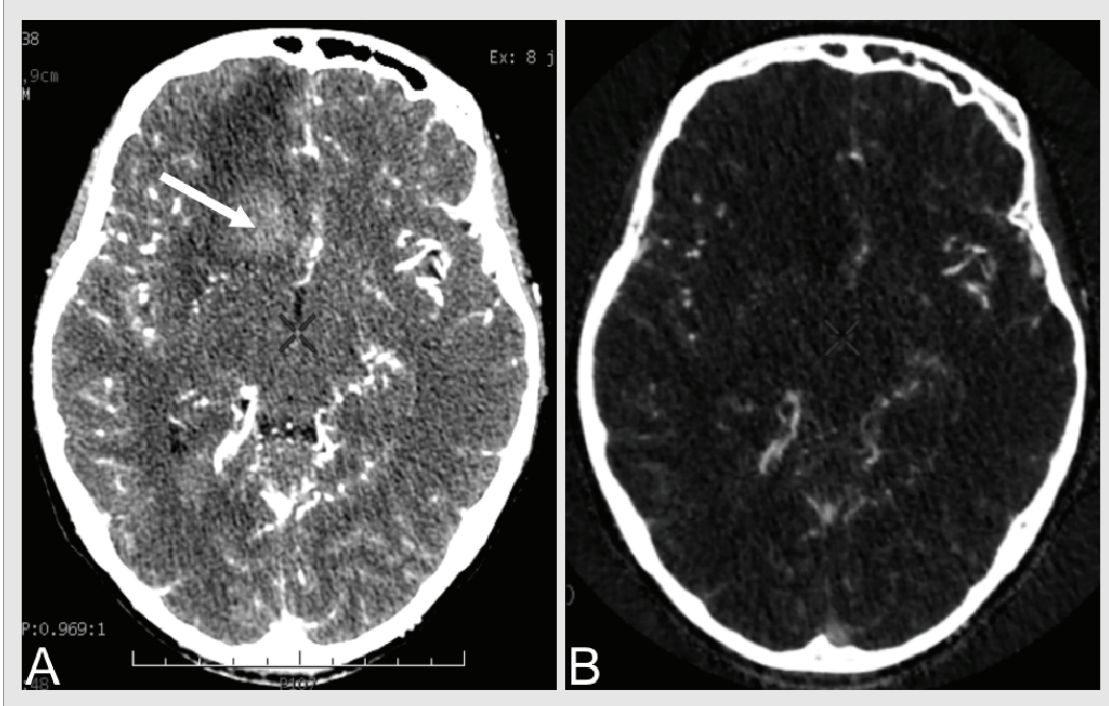

Fig. 15. Hyperdensity due to hemorrhage (white arrow) on mono energy $70 \mathrm{keV}$ images (A) is removed on iodine density image (B).

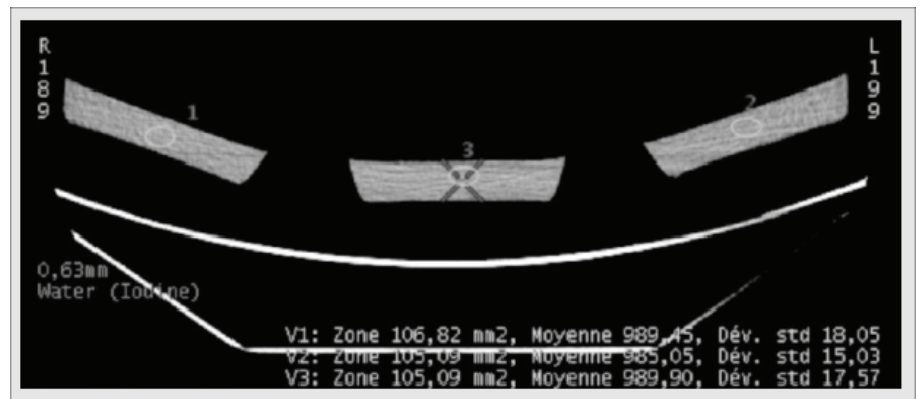

Fig. 16. Measurement of $1.1 \%$ agarose gel ( 3 samples) using post-processing on $65 \mathrm{keV}$ monochromatic image.

\section{Conclusion}

Most recent advance in medical CT imaging relies on dual-energy and improvement of travelling table system. They enable a more accurate evaluation of tissue density and brain perfusion, with a reduction of artefacts and an increase of cover thickness, retaining moderate radiation dose using suited reconstruction algorithms (ASIR).

\section{References}

Al-Tamimi, Yahia Z, Nicolas M Orsi, Audrey C Quinn, Shervanthi Homer-Vanniasinkam, et Stuart A Ross. 2010. A review of delayed ischemic neurologic deficit following 
aneurysmal subarachnoid hemorrhage: historical overview, current treatment, and pathophysiology. World Neurosurgery 73, nº 6 (Juin): 654-667. doi:10.1016/j.wneu. 2010.02.005.

Aviv, Richard I, Christopher D d'Esterre, Blake D Murphy, Julia J Hopyan, Brian Buck, Gabriella Mallia, Vivian Li, Liying Zhang, Sean P Symons, et Ting-Yim Lee. 2009. Hemorrhagic transformation of ischemic stroke: prediction with CT perfusion. Radiology 250, $\mathrm{n}^{\circ} .3$ (Mars): 867-877. doi:10.1148/radiol.2503080257.

Brenner, David J, et Eric J Hall. 2007. Computed tomography--an increasing source of radiation exposure. The New England Journal of Medicine 357, $\mathrm{n}^{\circ} .22$ (Novembre 29): 2277-2284. doi:10.1056/NEJMra072149.

Caire, F, Ph Derost, J Coste, J-M Bonny, F Durif, E Frenoux, A Villéger, et J-J Lemaire. 2006. [Subthalamic deep brain stimulation for severe idiopathic Parkinson's disease. Location study of the effective contacts]. Neuro-Chirurgie 52, $\mathrm{n}^{\circ} .1$ (Février): 15-25.

Coursey, Courtney A, Rendon C Nelson, Daniel T Boll, Erik K Paulson, Lisa M Ho, Amy M Neville, Daniele Marin, Rajan T Gupta, et Sebastian T Schindera. 2010. Dual-energy multidetector CT: how does it work, what can it tell us, and when can we use it in abdominopelvic imaging? Radiographics: A Review Publication of the Radiological Society of North America, Inc 30, nº 4 (Août): 1037-1055. doi:10.1148/rg.304095175.

Dankbaar, Jan Willem, Nicolien K de Rooij, Birgitta K Velthuis, Catharina J M Frijns, Gabriel J E Rinkel, et Irene C van der Schaaf. 2009. Diagnosing delayed cerebral ischemia with different CT modalities in patients with subarachnoid hemorrhage with clinical deterioration. Stroke; a Journal of Cerebral Circulation 40, $\mathrm{n}^{\circ} .11$ (Novembre): 3493-3498. doi:10.1161/STROKEAHA.109.559013.

Dawson, Peter. 2006. Functional imaging in CT. European Journal of Radiology 60, $\mathrm{n}^{\circ} .3$ (Décembre): 331-340. doi:10.1016/j.ejrad.2006.06.023.

Ding, Bei, Hua Wei Ling, Ke Min Chen, Hong Jiang, et Yan Bo Zhu. 2006. Comparison of cerebral blood volume and permeability in preoperative grading of intracranial glioma using CT perfusion imaging. Neuroradiology 48, $\mathrm{n}^{\circ} .10$ (Octobre): 773-781. doi:10.1007/s00234-006-0120-1.

Duffner, F, H Schiffbauer, S Breit, S Friese, et D Freudenstein. 2002. Relevance of image fusion for target point determination in functional neurosurgery. Acta Neurochirurgica 144, n. 5 (Mai): 445-451. doi:10.1007/s007010200065.

Ferroli, Paolo, Angelo Franzini, Carlo Marras, Elio Maccagnano, Ludovico D'Incerti, et Giovanni Broggi. 2004. A simple method to assess accuracy of deep brain stimulation electrode placement: pre-operative stereotactic CT + postoperative MR image fusion. Stereotactic and Functional Neurosurgery 82, $\mathrm{n}^{\circ} .1$ : 14-19. doi:10.1159/000076655.

Flicek, Kristina T, Amy K Hara, Alvin C Silva, Qing Wu, Mary B Peter, et C Daniel Johnson. 2010. Reducing the radiation dose for CT colonography using adaptive statistical iterative reconstruction: A pilot study. AJR. American Journal of Roentgenology 195, $\mathrm{n}^{\circ} .1$ (Juillet): 126-131. doi:10.2214/ AJR.09.3855.

Furtado, A D, B C Lau, E Vittinghoff, W P Dillon, W S Smith, T Rigby, L Boussel, et M Wintermark. 2010. Optimal brain perfusion CT coverage in patients with acute middle cerebral artery stroke. AJNR. American Journal of Neuroradiology 31, $\mathrm{n}^{\circ} .4$ (Avril): 691-695. doi:10.3174/ajnr.A1880. 
Gleason, C A, N F Kaula, H Hricak, R A Schmidt, et E A Tanagho. 1992. The effect of magnetic resonance imagers on implanted neurostimulators. Pacing and Clinical Electrophysiology: PACE 15, $\mathrm{n}^{\circ} .1$ (Janvier): 81-94.

Grand, S, V Lefournier, A Krainik, P Bessou, I Tropres, S Chabardes, D Hoffmann, et J-F Le Bas. 2007. [MR and CT perfusion imaging of the brain: principles and clinical applications]. Journal De Radiologie 88, n. 3 (Mars): 444-471.

Gupta, Rajiv, Catherine M Phan, Christianne Leidecker, Thomas J Brady, Joshua A Hirsch, Raul G Nogueira, et Albert J Yoo. 2010. Evaluation of Dual-Energy CT for Differentiating Intracerebral Hemorrhage from Iodinated Contrast Material Staining. Radiology (Août 2). doi:10.1148/radiol.10091806. http://www.ncbi.nlm.nih.gov/pubmed/20679449.

Hagiwara A. 2008. Volume Helical Shuttle- A technical description. GE internal scientific publication.

Hara, Amy K, Robert G Paden, Alvin C Silva, Jennifer L Kujak, Holly J Lawder, et William Pavlicek. 2009. Iterative reconstruction technique for reducing body radiation dose at CT: feasibility study. AJR. American Journal of Roentgenology 193, $\mathrm{n}^{\circ}$. 3 (Septembre): 764-771. doi:10.2214/AJR.09.2397.

Hemm, Simone, Jérôme Coste, Jean Gabrillargues, Lemlih Ouchchane, Laurent Sarry, François Caire, François Vassal, et al. 2009. Contact position analysis of deep brain stimulation electrodes on post-operative CT images. Acta Neurochirurgica 151, $\mathrm{n}^{\circ} .7$ (Juillet): 823-829; discussion 829. doi:10.1007/s00701-009-0393-3.

Hoeffner, Ellen G, Ian Case, Rajan Jain, Sachin K Gujar, Gaurang V Shah, John P Deveikis, Ruth C Carlos, B Gregory Thompson, Mark R Harrigan, et Suresh K Mukherji. 2004. Cerebral perfusion CT: technique and clinical applications. Radiology 231, $\mathrm{n}^{\circ} .3$ (Juin): 632-644. doi:10.1148/radiol.2313021488.

Hui P, Li J, Zhou C, Yu S, Lo G, Wang X, Cao H, Guo Y, Shen Y, 2010. Material decomposition with spectral imaging on HDCT: Phantom experiments.ECR 2010 C2990. European Society of Radiology - European Congress of Radiology, Vienna, March 4-8, 2010

Jain, R, S K Ellika, L Scarpace, L R Schultz, J P Rock, J Gutierrez, S C Patel, J Ewing, et T Mikkelsen. 2008. Quantitative estimation of permeability surface-area product in astroglial brain tumors using perfusion CT and correlation with histopathologic grade. AJNR. American Journal of Neuroradiology 29, $\mathrm{n}^{\circ} .4$ (Avril): 694-700. doi:10.3174/ajnr.A0899.

Johnson, Thorsten R C, Bernhard Krauss, Martin Sedlmair, Michael Grasruck, Herbert Bruder, Dominik Morhard, Christian Fink, et al. 2007. Material differentiation by dual energy CT: initial experience. European Radiology 17, nº 6 (Juin): 1510-1517. doi:10.1007/s00330-006-0517-6.

Langan DA. 2008. Gemstone Spectral Imaging. GE internal scientific publication.

Law, Meng, Stanley Yang, Hao Wang, James S Babb, Glyn Johnson, Soonmee Cha, Edmond A Knopp, et David Zagzag. 2003. Glioma grading: sensitivity, specificity, and predictive values of perfusion MR imaging and proton MR spectroscopic imaging compared with conventional MR imaging. AJNR. American Journal of Neuroradiology 24, $\mathrm{n}^{\circ} .10$ (Décembre): 1989-1998.

Leipsic, Jonathon, Troy M Labounty, Brett Heilbron, James K Min, G B John Mancini, Fay Y Lin, Carolyn Taylor, Allison Dunning, et James P Earls. 2010. Adaptive statistical 
iterative reconstruction: assessment of image noise and image quality in coronary CT angiography. AJR. American Journal of Roentgenology 195, $\mathrm{n}^{\circ} .3$ (Septembre): 649654. doi:10.2214/AJR.10.4285.

Lemaire, Jean-Jacques, Jérôme Coste, Lemlih Ouchchane, François Caire, et al. 2007.a. Brain mapping in stereotactic surgery: a brief overview from the probabilistic targeting to the patient-based anatomic mapping. NeuroImage 37 Suppl 1: S109-115. doi:10.1016/j.neuroimage.2007.05.055.

Lemaire, Jean-Jacques, Jérôme Coste, Lemlih Ouchchane, Simone Hemm, Philippe Derost, Miguel Ulla, Séverine Siadoux, Jean Gabrillargues, Franck Durif, et Jean Chazal. 2007.b. MRI anatomical mapping and direct stereotactic targeting in the subthalamic region: functional and anatomical correspondence in Parkinson's disease. International Journal of Computer Assisted Radiology and Surgery 2, n. 2 (7): 75-85. doi:10.1007/s11548-007-0124-2.

Ma, Rui, Cheng Liu, Kai Deng, Shao-juan Song, Dao-ping Wang, et Ling Huang. 2010. Cerebral artery evaluation of dual energy CT angiography with dual source CT. Chinese Medical Journal 123, n. 9 (Mai): 1139-1144.

McCollough, Cynthia H, Andrew N Primak, Natalie Braun, James Kofler, Lifeng Yu, et Jodie Christner. 2009. Strategies for reducing radiation dose in CT. Radiologic Clinics of North America 47, nº 1 (Janvier): 27-40. doi:10.1016/j.rcl.2008.10.006.

Mejdoubi, M, L Calviere, et H Dumas. 2010. [Value of CT perfusion for the diagnosis of early middle cerebral artery stroke]. Journal De Radiologie 91, $\mathrm{n}^{\circ} .5$ (Mai): 555-560.

Pham, M, A Johnson, A J Bartsch, C Lindner, W Müllges, K Roosen, L Solymosi, et M Bendszus. 2007. CT perfusion predicts secondary cerebral infarction after aneurysmal subarachnoid hemorrhage. Neurology 69, nº 8 (Août 21): 762-765. doi:10.1212/01.wnl.0000267641.08958.1b.

Pinto, Serge, Jean-François Le Bas, Laura Castana, Paul Krack, Pierre Pollak, et Alim-Louis Benabid. 2007. Comparison of two techniques to postoperatively localize the electrode contacts used for subthalamic nucleus stimulation. Neurosurgery $60, \mathrm{n}^{\circ} .4$ (Avril): 285-292; discussion 292-294. doi:10.1227/01.NEU.0000255353.64077.A8.

Prakash, Priyanka, Mannudeep K Kalra, Subba R Digumarthy, Jiang Hsieh, Homer Pien, Sarabjeet Singh, Matthew D Gilman, et Jo-Anne O Shepard. 2010. Radiation dose reduction with chest computed tomography using adaptive statistical iterative reconstruction technique: initial experience. Journal of Computer Assisted Tomography 34, $\mathrm{n}^{\circ} .1$ (Janvier): 40-45. doi:10.1097/RCT.0b013e3181b26c67.

Rutherford, R A, B R Pullan, et I Isherwood. 1976. Measurement of effective atomic number and electron density using an EMI scanner. Neuroradiology 11, $\mathrm{n}^{\circ}$. 1: 15-21.

Sagara, Yoshiko, Amy K Hara, William Pavlicek, Alvin C Silva, Robert G Paden, et Qing Wu. 2010. Abdominal CT: comparison of low-dose CT with adaptive statistical iterative reconstruction and routine-dose CT with filtered back projection in 53 patients. AJR. American Journal of Roentgenology 195, n. 3 (Septembre): 713-719. doi:10.2214/ AJR.09.2989.

Saliege M, Boyer-Grand A, Lemaire JJ, Chopineau J, Sautou V, Gabrillargues J, Coste A, Sakka L, Coste J, Tixier F, Martin C, Achim V. 2010. Agarose gels : model of artificial brain in neurosurgery.Therapeutic drug monitoring (TDM), ESCP10LYON-1860. Société Française de Pharmacie Clinique - European Symposium of Clinical Pharmacy (SFPC-ESCP), Lyon, Octobre 22-23, 2010. 
van der Schaaf, Irene C, Birgitta K Velthuis, Marieke J H Wermer, Nanne J Frenkel, Charles B L M Majoie, Theo D Witkamp, Gerard de Kort, Nicole J Freling, et Gabriel J E Rinkel. 2006. Multislice computed tomography angiography screening for new aneurysms in patients with previously clip-treated intracranial aneurysms: Feasibility, positive predictive value, and interobserver agreement. Journal of Neurosurgery 105, $n^{\circ} .5$ (Novembre): 682-688. doi:10.3171/jns.2006.105.5.682.

Schaefer, P W, L Roccatagliata, C Ledezma, B Hoh, L H Schwamm, W Koroshetz, R G Gonzalez, et M H Lev. 2006. First-pass quantitative CT perfusion identifies thresholds for salvageable penumbra in acute stroke patients treated with intraarterial therapy. AJNR. American Journal of Neuroradiology 27, $\mathrm{n}^{\circ} .1$ (Janvier): 20-25.

Scheithauer, Bernd W, Greg N Fuller, et Scott R VandenBerg. 2008. The 2007 WHO classification of tumors of the nervous system: controversies in surgical neuropathology. Brain Pathology (Zurich, Switzerland) 18, $\mathrm{n}^{\circ} .3$ (Juillet): 307-316. doi:10.1111/j.1750-3639.2008.00179.x.

Schramm, Peter, Peter D Schellinger, Ernst Klotz, Kai Kallenberg, Jochen B Fiebach, Sonja Külkens, Sabine Heiland, Michael Knauth, et Klaus Sartor. 2004. Comparison of perfusion computed tomography and computed tomography angiography source images with perfusion-weighted imaging and diffusion-weighted imaging in patients with acute stroke of less than 6 hours' duration. Stroke; a Journal of Cerebral Circulation 35, n. 7 (Juillet): 1652-1658. doi:10.1161/01.STR.0000131271.54098.22.

Schramm, Peter, Argyro Xyda, Ernst Klotz, Volker Tronnier, Michael Knauth, et Marius Hartmann. 2010. Dynamic CT perfusion imaging of intra-axial brain tumours: differentiation of high-grade gliomas from primary CNS lymphomas. European Radiology (Mai 22). doi:10.1007/s00330-010-1817-4. http://www.ncbi.nlm.nih.gov/pubmed/20495977.

Schueler, Beth A., Todd B. Parrish, Jyh-Cherng Lin, Bruce E. Hammer, Brian J. Pangrle, E. Russell Ritenour, John Kucharczyk, et Charles L. Truwit. 1999. MRI compatibility and visibility assessment of implantable medical devices. Journal of Magnetic Resonance Imaging 9, $\mathrm{n}^{\circ}$. 4 (4): 596-603. doi:10.1002/(SICI)15222586(199904)9:4<596::AID-JMRI14>3.0.CO;2-T.

Silva, Alvin C, Holly J Lawder, Amy Hara, Jennifer Kujak, et William Pavlicek. 2010. Innovations in CT dose reduction strategy: application of the adaptive statistical iterative reconstruction algorithm. AJR. American Journal of Roentgenology 194, nº 1 (Janvier): 191-199. doi:10.2214/ AJR.09.2953.

Sprawls Perry. Interaction of Radiation with Matter. In The Physical Principles of Medical Imaging. 2 éd. Sprawls Educational Foundation. Online textbook.

Uitti, Ryan J, Yoshio Tsuboi, Robert A Pooley, John D Putzke, Margaret F Turk, Zbigniew K Wszolek, Robert J Witte, et Robert E Wharen. 2002. Magnetic resonance imaging and deep brain stimulation. Neurosurgery 51, $\mathrm{n}^{\circ}$. 6 (Décembre): 1423-1428; discussion 1428-1431.

Vayssiere, Nathalie, Niels van der Gaag, Laura Cif, Simone Hemm, Regis Verdier, Philippe Frerebeau, et Philippe Coubes. 2004. Deep brain stimulation for dystonia confirming a somatotopic organization in the globus pallidus internus. Journal of Neurosurgery 101, n. 2 (Août): 181-188. doi:10.3171/jns.2004.101.2.0181.

Watanabe, Yoshiyuki, Kensuke Uotani, Tetsuro Nakazawa, Masahiro Higashi, Naoaki Yamada, Yoshiro Hori, Suzu Kanzaki, Tetsuya Fukuda, Toshihide Itoh, et Hiroaki 
Naito. 2009. Dual-energy direct bone removal CT angiography for evaluation of intracranial aneurysm or stenosis: comparison with conventional digital subtraction angiography. European Radiology 19, n. 4 (Avril): 1019-1024. doi:10.1007/s00330008-1213-5.

Wintermark, M, R Chiolero, G Van Melle, J P Revelly, F Porchet, L Regli, P Maeder, R Meuli, et $\mathrm{P}$ Schnyder. 2006. Cerebral vascular autoregulation assessed by perfusion-CT in severe head trauma patients. Journal of Neuroradiology. Journal De Neuroradiologie 33, $\mathrm{n}^{\circ} .1$ (Février): 27-37.

Wintermark, M, N U Ko, W S Smith, S Liu, R T Higashida, et W P Dillon. 2006. Vasospasm after subarachnoid hemorrhage: utility of perfusion CT and CT angiography on diagnosis and management. AJNR. American Journal of Neuroradiology 27, $\mathrm{n}^{\circ} .1$ (Janvier): 26-34.

Wintermark, Max, William P Dillon, Wade S Smith, Benison C Lau, Saadia Chaudhary, Songling Liu, Melissa $\mathrm{Yu}$, et al. 2008. Visual grading system for vasospasm based on perfusion CT imaging: comparisons with conventional angiography and quantitative perfusion CT. Cerebrovascular Diseases (Basel, Switzerland) 26, n . 2: 163170. doi:10.1159/000139664.

Wintermark, Max, Adam E Flanders, Birgitta Velthuis, Reto Meuli, Maarten van Leeuwen, Dorit Goldsher, Carissa Pineda, et al. 2006. Perfusion-CT assessment of infarct core and penumbra: receiver operating characteristic curve analysis in 130 patients suspected of acute hemispheric stroke. Stroke; a Journal of Cerebral Circulation 37, $\mathrm{n}^{\circ}$. 4 (Avril): 979-985. doi:10.1161/01.STR.0000209238.61459.39.

Wintermark, Max, Marc Reichhart, Jean-Philippe Thiran, Philippe Maeder, Marc Chalaron, Pierre Schnyder, Julien Bogousslavsky, et Reto Meuli. 2002. Prognostic accuracy of cerebral blood flow measurement by perfusion computed tomography, at the time of emergency room admission, in acute stroke patients. Annals of Neurology 51, $\mathrm{n}^{\circ} .4$ (Avril): 417-432.

Zaro-Weber, Olivier, Walter Moeller-Hartmann, Wolf-Dieter Heiss, et Jan Sobesky. 2009. The performance of MRI-based cerebral blood flow measurements in acute and subacute stroke compared with 15O-water positron emission tomography: identification of penumbral flow. Stroke; a Journal of Cerebral Circulation 40, n. 7 (Juillet): 2413-2421. doi:10.1161/STROKEAHA.108.540914. 


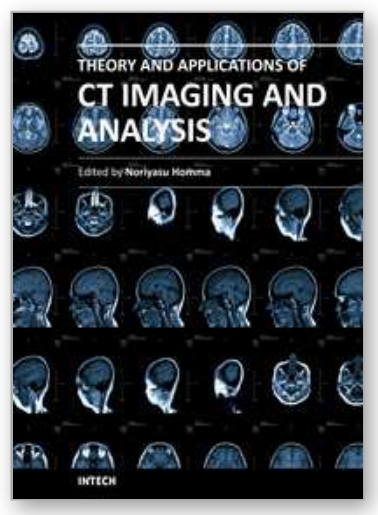

\author{
Theory and Applications of CT Imaging and Analysis \\ Edited by Prof. Noriyasu Homma
}

ISBN 978-953-307-234-0

Hard cover, 290 pages

Publisher InTech

Published online 04, April, 2011

Published in print edition April, 2011

The x-ray computed tomography (CT) is well known as a useful imaging method and thus CT images have continuingly been used for many applications, especially in medical fields. This book discloses recent advances and new ideas in theories and applications for CT imaging and its analysis. The 16 chapters selected in this book cover not only the major topics of CT imaging and analysis in medical fields, but also some advanced applications for forensic and industrial purposes. These chapters propose state-of-the-art approaches and cutting-edge research results.

\title{
How to reference
}

In order to correctly reference this scholarly work, feel free to copy and paste the following:

Béatrice Claise, Jean Gabrillargues, Emmanuel Chabert, Laurent Sakka, Toufik Khalil, Vivien Mendes-Martins, Viorel Achim, Jérôme Costes, Thierry Gillart and Jean-Jacques Lemaire (2011). Advanced Neuroimaging with Computed Tomography Scanning, Theory and Applications of CT Imaging and Analysis, Prof. Noriyasu Homma (Ed.), ISBN: 978-953-307-234-0, InTech, Available from: http://www.intechopen.com/books/theoryand-applications-of-ct-imaging-and-analysis/advanced-neuroimaging-with-computed-tomography-scanning

\section{INTECH}

open science | open minds

\author{
InTech Europe \\ University Campus STeP Ri \\ Slavka Krautzeka 83/A \\ 51000 Rijeka, Croatia \\ Phone: +385 (51) 770447 \\ Fax: +385 (51) 686166 \\ www.intechopen.com
}

\author{
InTech China \\ Unit 405, Office Block, Hotel Equatorial Shanghai \\ No.65, Yan An Road (West), Shanghai, 200040, China \\ 中国上海市延安西路65号上海国际贵都大饭店办公楼405单元 \\ Phone: +86-21-62489820 \\ Fax: +86-21-62489821
}


(C) 2011 The Author(s). Licensee IntechOpen. This chapter is distributed under the terms of the Creative Commons Attribution-NonCommercialShareAlike-3.0 License, which permits use, distribution and reproduction for non-commercial purposes, provided the original is properly cited and derivative works building on this content are distributed under the same license. 